\title{
A Cultural Dimensions Model based on Smart Phone Applications
}

\author{
Jung-Min Oh* and Nammee Moon*
}

\begin{abstract}
One of the major factors influencing the phenomenal growth of the smart phone market is the active development applications based on open environments. Despite difficulties in finding and downloading applications due to the small screens and inconvenient interfaces of smart phones, users download applications nearly every day. Such user behavior patterns indicate the significance of smart phone applications. So far, studies on applications have focused mainly on technical approaches, including recommendation systems. Meanwhile, the issue of culture, as an aspect of user characteristics regarding smart phone use, remains largely unexamined throughout the world.

Hence, the present study attempts to analyze the highest ranked smart phone applications downloaded and paid for that are ranked the highest in 10 countries (Korea, Japan, China, India, the UK, USA, Indonesia, Canada, France, and Mexico) and we then derive the CDSC (Cultural Dimensions Score of Content) for these applications. The results derived are, then, mapped to the cultural dimensions model to determine the CISC (Cultural Index Score for Country). Further, culturally significant differences in smart phone environments are identified using MDS analysis.
\end{abstract}

Keywords-Smart Phone, Culture, Cultural Dimensions Model, MDS, Mobile Application Analysis

\section{INTRODUCTION}

There are over 225,000 and nearly 500,000 applications for Apple and Android in distribution, respectively, in more than 90 countries worldwide. In general, users are assumed to choose and consume applications by individual preference, but a kind of consumption pattern has been discovered from the wider perspective of social groups. That is, many researchers have found that a latent culture lies beneath organizational and web environments, influencing individuals subliminally. User interface design and user behavior patterns have been subjects of studies regarding mobile environments. Considering the characteristics of smart phones, however, there is a wide range of applications that provide compelling motives for users to choose smart phones instead of ordinary cell phones. For that reason, more diverse cultural studies in terms of applications are required; but so far studies on applications have prioritized technical approaches, including recommendation systems $[1,2]$.

\footnotetext{
※ This work was supported by the Korea Science and Engineering Foundation (KOSEF) grant funded by the Korean government (MEST) (No. 2010-0000487)

Manuscript received August 20, 2010; accepted September 17, 2010.

Corresponding Author: Nammee Moon

* Dept. of IT Application Tech, Hoseo Graduate School of Venture, Seoul, Korea (aliibaba@naver.com, mnm@ hoseo.edu)
} 
Therefore, considering the significance of smart phone applications, the present study aims at a comparative cultural study focusing on applications for the iPhone from the App Store. This study is presented in the following sequence. First, a cultural dimensions model to provide the basic framework for the comparative cultural study is examined to build relevant cultural dimensions. Second, user propensities to download applications are quantitatively analyzed in 10 countries where smart phones are actively utilized. Third, a Delphi online survey is conducted to present correlations between the cultural dimensions model and the applications. Fourth, national and cultural characteristics are derived based on the results of analyses; they are then tested statistically.

\section{THEORETICAL BACKGROUND}

In this section, a conspectus of culture as the essential concept of the study is given.

\subsection{National Culture}

"Culture" is defined in varying ways. As of 1952, as many as 164 definitions of culture existed, implying a diverse set of meanings [3]. Still, at the core, culture refers to an integrated pattern of human knowledge, beliefs, and behavior, or a totality of common attitude, values, and goals distinguishing an organization or a group [3]. To be more specific, culture is the "transmitted and created content and patterns of values, ideas, and other symbolic-meaningful systems as factors in the shaping of human behavior and the artifacts produced through behavior" [4] and the "collective programming of the mind which distinguishes the members of one group or category of people from another"[5].

According to Hofstede [5], most people belong to various groups and organizations at the same time, which forms various layers of culture in different dimensions. For instance:

- at a national level, according to one's country

- at a regional/ethnic/religious/linguistic affiliation level,

- at a gender level, according to whether a person was born as a male of female,

- at a generation level, which separates grandparents and parents from children,

- at a social class level, associated with educational opportunities and with a person's occupation or profession, and

- at an organizational/corporate level, according to the way employees have been socialized by their work organization.

In the present study, the focus of discussion is placed on the national-level layer to identify the cultural characteristics of people from different countries.

\subsection{Cultural Dimensions Model}

To analyze the abstract concept of culture, comparative cultural studies have used dimensional models. 


\subsubsection{Hofstede’s Model}

The dimensions first suggested by Hofstede have most frequently been referred to in cultural studies [6, 7, 8, 9, 10,11, and 12]. Hofstede built a 4D culture model by means of a factor analysis on 50 countries [ 5,13 , and 14$]$. His dimensions are as follows:

Power distance: can be defined as the extent to which the less powerful members of institutions and organizations within a country expect and accept that power is distributed unequally.

Individualism versus collectivism: Individualism pertains to societies in which the ties between individuals are loose. Collectivism, as its opposite, pertains to societies in which people from birth onwards are integrated into strong, cohesive groups.

Masculinity versus femininity: Masculinity pertains to societies in which social gender roles are clearly distinct. Femininity pertains to societies in which social gender roles overlap.

Uncertainty avoidance: can be defined as the extent to which the members of a culture feel threatened by uncertain or unknown situations and try to avoid such situations.

It must be remembered that studies on differences between groups, cultures, and societies should assume cultural relativism [5, 15]. Cultural relativism becomes grounds for the assertion that individual behaviors or beliefs should be understood from the perspective of the culture to which those persons belong [16].

\subsubsection{Schwartz's Model}

Influenced by Hofstede's cultural dimension model, Schwartz suggested a new culture model based on values. For 4 years, beginning in 1988, Schwartz assessed a total of 86 values using school teachers, teens, undergraduates, and workers from 38 countries to derive 45 valid values and specified a total of 7 culture-level value types [17,18], as follows:

Conservatism: is constituted precisely of those values likely to be important in societies based on close-knit harmonious relations, in which the interests of the person are not viewed as distinct from those of the group.

Intellectual autonomy: is likely to be important in societies that view the persons as an autonomous entity entitled to pursue his or her individual interests and desires. Intellectual autonomy has a more intellectual emphasis on self-direction.

Affective autonomy: places a more affective emphasis on stimulation and hedonism.

Hierarchy: emphasizes the legitimacy of hierarchical roles and resource allocation. This value type forms the hypothesized broad self-enhancement region together with the next type, Mastery.

Mastery: emphasizes active mastery of the social environment through self-assertion. Mastery values promote active efforts to modify one's surroundings and get ahead of other people.

Egalitarian commitment: This is a social commitment that can occur among equals. It must be present for societies of autonomous individuals to function smoothly. Among people who share status obligations and kinship ties, adherence to such values is assumed and is not left to voluntary decisions that must be encouraged by cultural value exhortation.

Harmony: is related most closely to Egalitarian Commitment, with which it forms the broad self-transcendence region. "World at peace," "social justice," "helpful”could also be placed in the Harmony category.

Baack and Singh suggested that the two aforementioned models be integrated for the analysis and proposed integration between Collectivism and Conservatism; Power Distance and Hierarchy; and Masculinity and Mastery [19]. 


\section{ReseARCh Methodology}

In this section, the basic framework for a comparative study is designed and analytical data are specified. Then, a questionnaire survey, distributed to expert respondents, to derive a cultural dimensions model and data correlations is described.

\subsection{Framework of Cultural Dimensions}

Hofstede's (1991) and Schwartz's (1994) models provide conceptual and theoretical frameworks in comparative cultural studies. Thus, in lieu of choosing and applying individual models, it is appropriate to integrate these two models for analysis [19]. In the present paper, 1) Individualism versus Collectivism (IDV), 2) Intellectual autonomy (INA), 3) Affective autonomy (AFA), 4) Hierarchy (HRC) 5) Masculinity versus Femininity (MAS), 6) Interactivity(INT) are added together to build a six-dimensional cultural model. Each dimension is briefly defined in Table 1.

Table 1. Definition of cultural dimensions

\begin{tabular}{c|c|l}
\hline No & Dimension & \multicolumn{1}{|c}{ Definition } \\
\hline 1 & IDV & Interested more in content related to individuals and immediate family. \\
\hline 2 & INA & Interested more in acquiring and generating knowledge and something logical. \\
\hline 3 & AFA & Interested more in something provocative, playful, exhaustive, and pleasing. \\
\hline 4 & HRC & Less resistant to the content associated with social class and authority. \\
\hline 5 & MAS & $\begin{array}{l}\text { Having distinct gender roles and preferring content regarding success, achievement, and } \\
\text { persuasion. }\end{array}$ \\
\hline 6 & INT & $\begin{array}{l}\text { Preferring user-oriented communication, such as replies and recommendations and ex- } \\
\text { pressing opinions. }\end{array}$ \\
\hline
\end{tabular}

\subsection{Data Sample}

A total of 10 countries out of 92 smart phone-using countries were chosen for analysis: the USA, India, Indonesia, England, Canada, Japan, France, China, Mexico, and Korea, where the proportions of smart phone use were high as of May 2010 [20, 21]. The analysis took place during the month of August, and a total of 4 analyses were conducted. As for the method of analysis, the 300 top paid applications in those 10 countries were categorized and mean data were extracted four times. For the analysis, the Apple-provided “iTunes Store RSS Feed Generator” was applied.

Figure 1 shows sample screens of the categories provided in the App Store for smart phones.

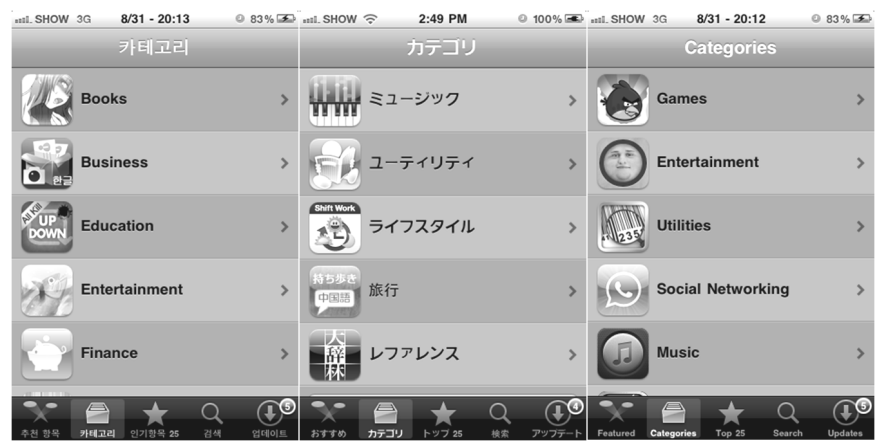

Fig. 1. Category screen shots of the app. store (Korea, Japan, and USA) 


\subsection{Delphi Survey}

To derive correlations between the cultural dimensions model and applications, an online questionnaire survey was conducted. Respondents were limited to workers, professors, and researchers who have been in the web-related field for over 10 years. The expert respondents were asked to rate the degree of cultural dimensions reflected in 20 categories on 5-point Likert scales. A total of 18 questionnaires were returned; two respondents, who did not use smart phones, were excluded. As a result, data obtained from 16 respondents were used. The gender ratio among the respondents was $38 \%$ males and $62 \%$ females. Regarding the ages of respondents, 12 and 4 of the respondents were in their 30 s and 40 s, respectively.

\section{RESULtS}

In this chapter, the results of the analyses of the top paid applications with the study method adopted here and those of the Delphi survey are discussed. Based on these results, the cultural dimensions model is applied to each country.

\subsection{Descriptive Statistics}

Based on the data gathered, a national frequency analysis was performed. Table 2 shows the statistics of basic consumption of applications in each country, indicating patterns in consuming 300 applications in 20 categories. In Canada, for example, the maximum 170.3 applications are consumed in one category.

Table 3 shows the details of application download patterns in each country.

The proportions of downloads in one category are marked with different types of circles for ease of understanding. Among the categories accounting for at least 25\%, the Games category is intensely preferred in the majority of countries, except Korea. Due to legal issues, the Games category is not available in Korea, this seems to have lead the Entertainment category to be used there more than in the other countries.

The Utilities category shows an even distribution across the countries. Such categories as Books, Education, Music, Photography, and Productivity show differences among the countries. These categories are associated with knowledge acquisition and productivity. Asian

Table 2. Descriptive statistics

\begin{tabular}{c|c|c|c|c}
\hline Country & Mean & Std. Deviation & Minimum & Maximum \\
\hline Korea & 15.000 & 19.8133 & 0.0 & 88.8 \\
\hline Japan & 15.000 & 19.7764 & 0.8 & 89.0 \\
\hline China & 15.000 & 23.3104 & 0.5 & 105.3 \\
\hline India & 15.000 & 28.5947 & 0.0 & 128.0 \\
\hline UK & 15.000 & 34.2734 & 0.0 & 157.0 \\
\hline USA & 15.000 & 34.0908 & 0.5 & 155.3 \\
\hline Indonesia & 15.000 & 36.0566 & 0.0 & 165.0 \\
\hline Canada & 15.000 & 37.3519 & 0.0 & 170.3 \\
\hline France & 15.000 & 29.9619 & 0.5 & 136.3 \\
\hline Mexico & 15.000 & 34.4907 & 0.8 & 157.8 \\
\hline
\end{tabular}


Table 3. Analysis of frequency in application downloads $(* \circ: 4 \%$ / () : 5\% 24\% / $: 25 \% \sim 49 \%$ /

\begin{tabular}{|c|c|c|c|c|c|c|c|c|c|c|c|c|c|c|c|c|c|c|c|c|}
\hline \multirow{2}{*}{ Top Paid Apps } & \multicolumn{2}{|c|}{ Korea } & \multicolumn{2}{|c|}{ Japan } & \multicolumn{2}{|c|}{ China } & \multicolumn{2}{|c|}{ India } & \multicolumn{2}{|c|}{ UK } & \multicolumn{2}{|c|}{ USA } & \multicolumn{2}{|c|}{ Indonesia } & \multicolumn{2}{|c|}{ Canada } & \multicolumn{2}{|c|}{ France } & \multicolumn{2}{|c|}{ Mexico } \\
\hline & quantity & $\%$ & quantity & $\%$ & quantity & $\%$ & quântity & $\%$ & quantity & $\%$ & quantity & $\%$ & quantity & $\%$ & guantity & $\%$ & quantity & $\%$ & quantity & $\%$ \\
\hline Books & (0) & $6 \%$ & (0) & $10 \%$ & (0) & $9 \%$ & 0 & $2 \%$ & 0 & $1 \%$ & 0 & $1 \%$ & 0 & $2 \%$ & 0 & $1 \%$ & 0 & $0 \%$ & 0 & $3 \%$ \\
\hline Business & 0 & $3 \%$ & 0 & $3 \%$ & 0 & $2 \%$ & 0 & $2 \%$ & 0 & $0 \%$ & 0 & $0 \%$ & 0 & $2 \%$ & 0 & $1 \%$ & 0 & $0 \%$ & 0 & $1 \%$ \\
\hline Education & (0) & $12 \%$ & 0 & $4 \%$ & (0) & $5 \%$ & 0 & $2 \%$ & 0 & $2 \%$ & 0 & $2 \%$ & 0 & $1 \%$ & 0 & $1 \%$ & 0 & $4 \%$ & 0 & $4 \%$ \\
\hline Entertạinment & 1 & $30 \%$ & (0) & $9 \%$ & (0) & $9 \%$ & (0) & $12 \%$ & (0) & $11 \%$ & (0) & $11 \%$ & (0) & $8 \%$ & (0) & $10 \%$ & (9) & $11 \%$ & (0) & $11 \%$ \\
\hline Finance & 0 & $2 \%$ & 0 & $2 \%$ & 0 & $2 \%$ & 0 & $1 \%$ & 0 & $0 \%$ & 0 & $0 \%$ & 0 & $1 \%$ & 0 & $0 \%$ & 0 & $0 \%$ & 0 & $1 \%$ \\
\hline Games & 0 & $0 \%$ & 0 & $30 \%$ & 0 & $35 \%$ & ( & $43 \%$ & 0 & $52 \%$ & 0 & $52 \%$ & 0 & $55 \%$ & 0 & $57 \%$ & 0 & $45 \%$ & 0 & $53 \%$ \\
\hline Healtheare\&Fitne & 0 & $3 \%$ & 0 & $3 \%$ & 0 & $1 \%$ & 0 & $1 \%$ & 0 & $3 \%$ & 0 & $4 \%$ & 0 & $1 \%$ & 0 & $4 \%$ & 0 & $3 \%$ & 0 & $2 \%$ \\
\hline Lifestyle & (0) & $8 \%$ & 0 & $3 \%$ & 0 & $4 \%$ & 0 & $4 \%$ & 0 & $2 \%$ & 0 & $3 \%$ & 0 & $2 \%$ & 0 & $3 \%$ & 0 & $2 \%$ & 0 & $4 \%$ \\
\hline Medical & 0 & $0 \%$ & 0 & $0 \%$ & 0 & $1 \%$ & 0 & $0 \%$ & 0 & $0 \%$ & 0 & $0 \%$ & 0 & $0 \%$ & 0 & $0 \%$ & 0 & $1 \%$ & 0 & $0 \%$ \\
\hline Music & (0) & $6 \%$ & 0 & $4 \%$ & (0) & $5 \%$ & 0 & $4 \%$ & 0 & $4 \%$ & 0 & $4 \%$ & 0 & $3 \%$ & 0 & $4 \%$ & 0 & $3 \%$ & 0 & $4 \%$ \\
\hline Navigation & 0 & $2 \%$ & 0 & $2 \%$ & 0 & $1 \%$ & 0 & $1 \%$ & 0 & $2 \%$ & 0 & $1 \%$ & 0 & $1 \%$ & 0 & $2 \%$ & 0 & $2 \%$ & 0 & $1 \%$ \\
\hline News & 0 & $1 \%$ & 0 & $1 \%$ & 0 & $0 \%$ & 0 & $0 \%$ & 0 & $0 \%$ & 0 & $1 \%$ & 0 & $0 \%$ & 0 & $0 \%$ & 0 & $1 \%$ & 0 & $0 \%$ \\
\hline Photography & 0 & $5 \%$ & (0) & $9 \%$ & 0 & $4 \%$ & (0) & $5 \%$ & 0 & $3 \%$ & 0 & $4 \%$ & (0) & $5 \%$ & 0 & $3 \%$ & (0) & $5 \%$ & (0) & $4 \%$ \\
\hline Productivity & (0) & $5 \%$ & (0) & $8 \%$ & 0 & $3 \%$ & (0) & $7 \%$ & 0 & $3 \%$ & 0 & $4 \%$ & (0) & $5 \%$ & 0 & $3 \%$ & 0 & $3 \%$ & 0 & $3 \%$ \\
\hline Reference & 0 & $3 \%$ & 0 & $1 \%$ & 0 & $2 \%$ & 0 & $2 \%$ & 0 & $2 \%$ & 0 & $1 \%$ & 0 & $2 \%$ & 0 & $1 \%$ & 0 & $2 \%$ & 0 & $1 \%$ \\
\hline Social Networking & 0 & $2 \%$ & 0 & $2 \%$ & 0 & $2 \%$ & 0 & $2 \%$ & 0 & $2 \%$ & 0 & $2 \%$ & 0 & $4 \%$ & 0 & $2 \%$ & 0 & $3 \%$ & 0 & $2 \%$ \\
\hline Sports & 0 & $1 \%$ & 0 & $0 \%$ & 0 & $0 \%$ & 0 & $0 \%$ & 0 & $2 \%$ & 0 & $1 \%$ & 0 & $0 \%$ & 0 & $1 \%$ & 0 & $1 \%$ & 0 & $0 \%$ \\
\hline Travel & 0 & $3 \%$ & 0 & $1 \%$ & 0 & $2 \%$ & 0 & $1 \%$ & 0 & $3 \%$ & 0 & $0 \%$ & 0 & $1 \%$ & 0 & $0 \%$ & 0 & $1 \%$ & 0 & $1 \%$ \\
\hline Utilities & (0) & $8 \%$ & (0) & $7 \%$ & 0 & $12 \%$ & (0) & $11 \%$ & (0) & $7 \%$ & (0) & $8 \%$ & (0) & $8 \%$ & 0 & $8 \%$ & (0) & $11 \%$ & (0) & $7 \%$ \\
\hline Weather & 0 & $1 \%$ & 0 & $0 \%$ & 0 & $1 \%$ & 0 & $0 \%$ & 0 & $0 \%$ & 0 & $1 \%$ & 0 & $0 \%$ & 0 & $0 \%$ & 0 & $1 \%$ & 0 & $0 \%$ \\
\hline
\end{tabular}

countries such as Korea, Japan and China show high preferences for Books and Education categories.

\subsection{Adaptation to Cultural Dimensions}

\subsubsection{Survey analysis}

Based on the findings from the analysis of the Delphi survey, the Cultural Dimensions Score of Content (CDSC) usable on smart phones was calculated. This is an extended application of web content suggested by a previous study [22], to represent scores of how far application categories include the cultural dimensions model, or the attributes of IDV, INA, AFA, HRC, MAS and INT.

To calculate the CDSC, expression 1, below, is applied [22]:

$$
\operatorname{CSC}=\left(\sum_{\mathrm{i}=1}^{\mathrm{j}} \mathrm{i} * \mathrm{n}_{\mathrm{i}}\right) / \mathrm{N}
$$

(i: Likert scale $(1=<i<=j, j=5)$, ni: the number of responses of the given scale (i), $N$ : total number of all responses).

Table 4 presents the CDSC results obtained with the Delphi survey. The Finance category is high in IDV, the Education category is high in INA and the Games category is high in AFA. The News category is associated with high HRC and the Finance category with the highest MAS. Finally, the Social Networking category shows the highest INT. 
Table 4. Cultural Dimensions Score of Content (application)

\begin{tabular}{c|c|c|c|c|c|c}
\hline & \multicolumn{7}{|c}{ Cultural Dimensions Score of Content(Application) } \\
\hline App Category & IDV & INA & AFA & HRC & MAS & INT \\
\hline Books & 3.63 & 3.81 & 2.69 & 2.88 & 3.06 & 3.25 \\
\hline Business & 3.50 & 3.50 & 2.06 & 3.25 & 3.56 & 2.88 \\
\hline Education & 4.00 & 4.31 & 2.88 & 3.06 & 3.44 & 2.75 \\
\hline Entertainment & 3.31 & 2.13 & 4.56 & 2.94 & 2.31 & 3.75 \\
\hline Finance & 4.69 & 3.94 & 1.81 & 3.13 & 3.94 & 2.25 \\
\hline Games & 3.81 & 2.06 & 4.63 & 2.81 & 3.00 & 3.44 \\
\hline Healthcare \& Fitness & 4.00 & 2.88 & 3.13 & 3.13 & 3.31 & 3.19 \\
\hline Lifestyle & 3.63 & 2.44 & 3.81 & 2.81 & 2.56 & 3.31 \\
\hline Medical & 3.94 & 3.63 & 2.38 & 3.00 & 2.69 & 2.81 \\
\hline Music & 3.81 & 2.50 & 3.94 & 2.75 & 2.69 & 3.38 \\
\hline Navigation & 3.69 & 3.63 & 2.56 & 2.88 & 3.06 & 2.69 \\
\hline News & 2.50 & 4.13 & 3.13 & 3.69 & 3.31 & 3.06 \\
\hline Photography & 4.06 & 2.81 & 4.19 & 2.69 & 2.94 & 3.38 \\
\hline Productivity & 4.13 & 4.06 & 2.75 & 3.31 & 3.88 & 3.19 \\
\hline Reference & 3.88 & 4.19 & 2.50 & 3.00 & 3.69 & 2.75 \\
\hline Social Networking & 3.38 & 3.19 & 3.94 & 3.44 & 3.13 & 4.56 \\
\hline Sports & 3.19 & 2.31 & 4.38 & 3.44 & 2.63 & 3.44 \\
\hline Travel & 3.56 & 3.63 & 3.44 & 3.06 & 2.94 & 3.38 \\
\hline Utilities & 3.75 & 3.56 & 2.81 & 2.81 & 3.44 & 2.69 \\
\hline Weather & 3.13 & 3.44 & 2.44 & 2.63 & 2.56 & 2.44 \\
\hline
\end{tabular}

\subsubsection{Cultural dimensions analysis}

Now, using the results regarding how far the cultural dimensions model is reflected in the applications, the national Cultural Index Score for Country (CISC) is derived. The CISC refers to the numbers from the cultural dimensions model found in each country based on the information on applications or content preferred in each country.

To calculate the CISC, expression 2, below, is used [22]:

$$
\text { CISC }=\sum_{a=1}^{b} \operatorname{CSC}_{a} * \frac{d m a}{D M}
$$

(a: category of application, dm: amount of data given, DM: total amount of data information)

Table 5 shows the calculated CISCs for 10 countries.

IDV is high in order in Japan, Indonesia, India, and Canada. In contrast, in Korea, England, China, and France, the collectivism index tends to be higher. Compared to Hofstede's index, the index in Korea, China, India, and Canada shows little change. The Individualism index rises in Japan and Indonesia and drops in England and the USA. However, these findings are in order of ranks, and the gaps between actual indices are narrow, resulting in only slight cultural differences between countries ranking high or low.

In terms of INA, Korea, Japan, China, India, and France rank high. Asian countries top the list, reflecting unusually high enthusiasm for education. AFA is high in order in Canada, England, 
Table 5. Cultural index score for countries

\begin{tabular}{|c|c|c|c|c|c|c|c|c|c|c|c|}
\hline & & Korea & Japan & China & India & UK & USA & Indonesia & Canada & France & Mexico \\
\hline \multirow{3}{*}{ IDV } & Index & 3.66 & 3.78 & 3.75 & 3.76 & 3.74 & 3.75 & 3.77 & 3.76 & 3.75 & 3.75 \\
\hline & Ranking & 10 & 1 & $5-8$ & $3-4$ & 9 & $5-8$ & 2 & $3-4$ & $5-8$ & $5-8$ \\
\hline & Hofstede's & $18(9)$ & $46(6)$ & $20(8)$ & 485 & $89(2)$ & $91(1)$ & $14(10)$ & $80(3)$ & $71(4)$ & $30(7)$ \\
\hline \multirow{3}{*}{ INA } & Index & 3.07 & 2.94 & 2.86 & 2.68 & 2.52 & 2.52 & 2.57 & 2.47 & 2.65 & 2.54 \\
\hline & Ranking & 1 & 2 & 3 & 4 & $8-9$ & 8-9 & 6 & 10 & 5 & 7 \\
\hline & Schwartz's & - & $4.68(2)$ & $4.27(3)$ & - & - & $4.20(4-5)$ & - & - & $5.15(1)$ & $4.20(4-5)$ \\
\hline \multirow{3}{*}{ AFA } & Index & 3.54 & 3.68 & 3.73 & 3.94 & 4.13 & 4.12 & 4.09 & 4.15 & 4.00 & 4.11 \\
\hline & Ranking & 10 & 9 & 8 & 7 & 2 & 3 & 5 & 1 & 6 & 4 \\
\hline & Schwartz's & - & $3.54(3)$ & $3.32(4)$ & - & - & $3.65(2)$ & - & - & $4.41(1)$ & $3.23(5)$ \\
\hline \multirow{4}{*}{ HRC } & Index & 2.96 & 2.93 & 2.89 & 2.89 & 2.89 & 289 & 2.89 & 2.87 & 2.89 & 2.88 \\
\hline & Ranking & 1 & 2 & $3-8$ & $3-8$ & $3-8$ & $3-8$ & $3-8$ & 10 & $3-8$ & 9 \\
\hline & Hofstede's & $60(6)$ & $54(7)$ & $80(2)$ & $77(4)$ & $35(10)$ & $40(8)$ & $78(3)$ & $39(9)$ & $68(5)$ & $81(1)$ \\
\hline & Schwartz's & - & $2.86(2)$ & $3.70(1)$ & - & - & $2.39(3)$ & - & - & $2.16(5)$ & $2.35(4)$ \\
\hline \multirow{3}{*}{ MAS } & Index & 2.94 & 3.09 & 3.05 & 3.04 & 2.98 & 2.99 & 3.04 & 2.99 & 3.02 & 2.99 \\
\hline & Ranking & 10 & 1 & 2 & $3-4$ & 9 & $6-8$ & $3-4$ & $6-8$ & 5 & $6-8$ \\
\hline & Hofstede's & $39(10)$ & $95(1)$ & $66(3-4)$ & $56(6)$ & $66(3-4)$ & $62(5)$ & $46(8)$ & $52(7)$ & $43(9)$ & $69(2)$ \\
\hline \multirow{2}{*}{ INT } & Index & 3.27 & 3.28 & 3.25 & 3.31 & 3.37 & 3.36 & 3.37 & 3.36 & 3.31 & 3.36 \\
\hline & Ranking & 9 & 8 & 10 & $6-7$ & $1-2$ & $3-5$ & $1-2$ & $3-5$ & $6-7$ & $3-5$ \\
\hline
\end{tabular}

the USA, and Mexico. High preferences for games are highly associated with AFA. HRC is high in Korea and Japan. HRC is one of the indices that do not show much difference between countries. MAS is high in Japan, China, India and Indonesia. MAS results show a somewhat similar tendency to IDV results and an opposite tendency to AFA. Lastly, INT index is high in England, Indonesia, Canada, the USA, and Mexico.

Table 5 shows a comparison of Hofstede's and Schwartz's model for each cultural dimension. Here, existing national indices are marked, with national ranks placed in parentheses.

\subsection{Multi-dimensional Analysis}

The analytic quantification of the cultural dimensions model indicates that each country has intrinsic characteristics in their patterns of smart phone use. In addition, certain countries are found to have similar cultural characteristics. In fact, to verify what intrinsic meanings are assumed by the findings derived in the present study, a multi-dimensional scaling (MDS) was conducted. MDS is a methodology used to visually represent individual objects based on criteria in a multi-dimensional space by finding out hidden structures in data and the criteria of similarity-dissimilarity in the structures [23]. MDS is preferred in that subjectivity is excluded in analyzing the positioning of objects and potential attributes are identified [24].

As a result of applying ALSCAL MDS to the proportions of applications derived in the 10 countries above, the stress value is a good fit with the model with $0.06(>0.5)$, and RSQ is very high in the explanatory power of the model with $0.99658(>0.6)$.

- For matrix

Stress $=.06011 \quad$ RSQ $=.99658$

In Figure 2, the MDS-based positions of each country are plotted on a two dimensional plane. In MDS, objects having common characteristics are closely located and aligned along coordinate axes. These are normalized based on Euclidean distance.

In Dimension 1, Korea, Japan, and China are located in the positive quadrant, while the negative coordinate quadrants contain Canada, England, the USA, Indonesia, Mexico, and France. 


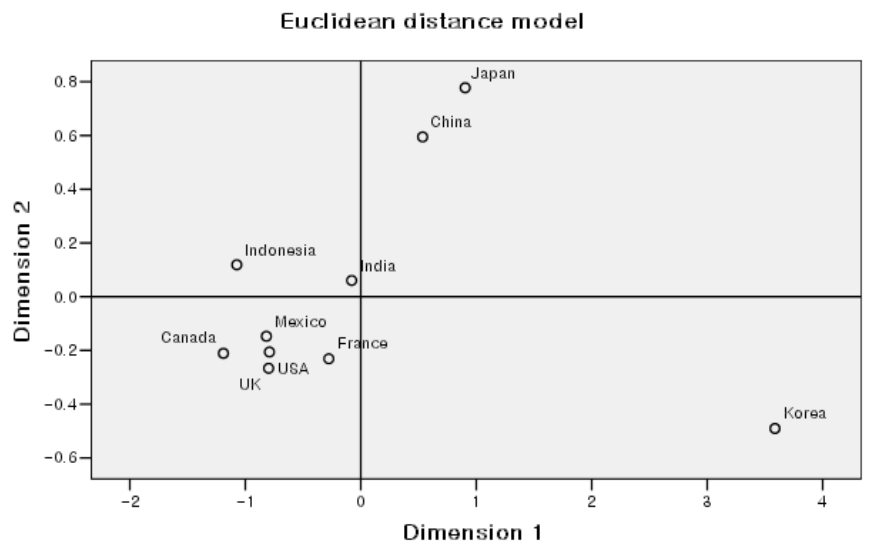

Fig. 2. ALSCAL MDS of symmetrical normalization

Table 6. Transformed Proximities of the country

\begin{tabular}{c|c|c|c|c|c|c|c|c|c|c}
\hline & Korea & Japan & China & India & UK & USA & Indonesia & Canada & France & Mexico \\
\hline Korea & .000 & & & & & & & & & \\
\hline Japan & 1.496 & .000 & & & & & & & & \\
\hline China & 1.519 & .251 & .000 & & & & & & & \\
\hline India & 1.804 & .568 & .353 & .000 & & & & & & \\
\hline UK & 2.000 & .985 & .745 & .431 & .000 & & & & & \\
\hline USA & 2.034 & .946 & .716 & .381 & .094 & .000 & & & & \\
\hline Indonesia & 2.225 & 1.051 & .843 & .491 & .276 & .204 & .000 & & & \\
\hline Canada & 2.192 & 1.145 & .915 & .578 & .194 & .199 & .201 & .000 & & \\
\hline France & 1.771 & .714 & .469 & .210 & .281 & .275 & .455 & .465 & .000 & \\
\hline Mexico & 2.098 & .927 & .714 & .363 & .215 & .121 & .132 & .247 & .328 & .000 \\
\hline
\end{tabular}

India is close to 0, meaning a neutral position. In other words, Dimension 1 implies intellectual activity (versus affective activity). In Dimension 2, the positive coordinates are occupied by Japan, China, Indonesia, and India; while the negative coordinates are occupied by the other countries (Dimension 2 implies masculinity).

Using PROXCAL, an MDS analysis method, proximity between the countries can be quantified. Table 6 shows the distance values between countries. The smaller number values in Table 6 indicated higher similarities. Korea is closest to Asian countries such as Japan (1.496) and China (1.519) as well as to France (1.771) and India (1.804). The closest distance values exist between England and the USA (0.94). The farthest distance values exist between Korea and Indonesia (2.225).

\subsection{Dimension Comparisons}

The CISC results derived implicate correlations between dimensions. To find out what correlations were present between dimensions, Pearson correlation coefficients were found and are shown in Table 7, below. 
Table 7. Pearson Correlation of the cultural dimensions

\begin{tabular}{c|c|c|c|c|c|c|c}
\hline \multicolumn{2}{l|}{} & IDV & INA & AFA & HRC & MAS & INT \\
\hline IDV & Pearson Correlation & 1 & .134 & -.279 & -.345 & $.453\left(^{*}\right)$ & -.303 \\
\hline & Sig. (2-tailed) & & .572 & .233 & .137 & .045 & .194 \\
\hline INA & Pearson Correlation & .134 & 1 & $-.812\left(^{* *}\right)$ & .287 & $.691\left(^{* *}\right)$ & $-.533(*)$ \\
\hline & Sig. (2-tailed) & .572 & & .000 & .220 & .001 & .016 \\
\hline AFA & Pearson Correlation & -.279 & $-.812\left(^{* *}\right)$ & 1 & -.063 & $-.605\left(^{* *}\right)$ & $.765\left(^{* *}\right)$ \\
\hline & Sig. (2-tailed) & .233 & .000 & & .791 & .005 & .000 \\
\hline HRC & Pearson Correlation & -.345 & .287 & -.063 & 1 & .377 & .249 \\
\hline MAS & Sig. (2-tailed) & .137 & .220 & .791 & & .102 & .289 \\
\hline & Pearson Correlation & $.453(*)$ & $.691(* *)$ & $-.605(* *)$ & .377 & 1 & -.382 \\
\hline INT & Sig. (2-tailed) & .045 & .001 & .005 & .102 & & .096 \\
\hline & Pearson Correlation & -.303 & $-.533(*)$ & $.765(* *)$ & .249 & -.382 & 1 \\
\hline
\end{tabular}

* Correlation is significant at the 0.05 level (2-tailed).

** Correlation is significant at the 0.01 level (2-tailed).

As seen in the abovementioned CISC, at the confidence level of 0.05 , IDV is correlated positively with MAS $(\mathrm{P}=0.453)$. INA is negatively correlated with AFA $(\mathrm{P}=-0.812)$ and INT $(\mathrm{P}=-$ $0.533)$, but positively correlated with MAS $(\mathrm{P}=0.691)$. The negative correlation between INA and AFA agrees with the findings reported by Schwartz [94Sch]. AFA is negatively correlated with MAS ( $\mathrm{P}=-0.605)$, but positively correlated with INT $(\mathrm{P}=0.765)$. In other words, INT and INA are negatively correlated $(\mathrm{P}=-0.533)$, while INT and AFA are positively correlated $(\mathrm{P}=0.765)$. These findings indicate that correlations in the INT dimension agree with the cultural dimensions suggested by previous studies.

\section{CONCLUSIONS AND FUtURE WORK}

The findings in the present study can be summarized by the following points.

First, the distribution of major applications differ across the 10 countries studied (Korea, the U.S., India, Indonesia, England, Canada, Japan, France, China, and Mexico). Due to the characteristics of smart phones as devices individually carried and leisurely used, preferences for Games and Entertainment categories were found high in all of the 10 countries. In contrast, preferences for Books, Education, and Lifestyle categories were found to be high in Korea. Asian countries showed high preferences for education-related applications.

Second, Hofstede's and Schwartz's culture models were applied here to build the six cultural dimensions as the basic framework for analysis. To analyze the correlations between applications and cultural dimensions, an online Delphi survey was performed. The Delphi survey found IDV is highest in the Finance category and INA in the Education category. Also, AFA and HRC are highest in Games and Entertainment and News Categories, respectively. MAS is highest in the Finance category as IDV. Finally, INT is highest in the Social Networking category.

Third, the national CISC (Cultural Index Score for Country) was derived with a cross-tab analysis of the two qualitative and quantitative results. CISC provides data suggesting that the cultural characteristics reported in Hofstede's and Schwartz's studies have changed. This indicates that existing socio-cultural environments have moved to online and mobile environments, 
causing gradual changes in culture.

Fourth, an MDS analysis was conducted to visually represent correlations between national patterns in using smart phone applications on a $2 \mathrm{D}$ plane, and the resulting data were verified with quantified distance values.

Fifth, five dimensions replicated from previous studies (IDV, INA, AFA, HRC, and MAS) and an additional dimension, INT, adopted here, have correlations based on Pearson correlation coefficients. INT is negatively and positively correlated with INA and AFA, respectively. Also, the five dimensions have correlations, so the cultural dimensions model derived here has an aspect that improves upon Hofstede's and Schwartz's models.

Meanwhile, the present study has the following limitations.

By considering the paid for applications only, this study excluded free applications that users download more frequently and easily. This is because user intention was considered to intervene further when they pay for applications, but different meanings could be found if free applications had been included.

Despite such limitations, the present study is meaningful in that comparative cultural characteristics suggested by previous studies were applied to smart phone applications for analysis, and the smart phone consumption environment was found to reflect national cultural characteristics. Further, the present study provides a broader cultural perspective by deriving cultural dimension indices in 10 countries.

Future studies will delve into the three-screen culture, integrating web, mobile and TV to analyze culture from the perspective of environmental changes as well as using recommendation systems taking culture into consideration to enhance the usability of mobile terminals.

\section{REFERENCES}

[1] P. Won-Ik, S. Woo-Je, “A Mobile Multimedia Contents Recommendation Technique Considering User's Psychological Patterns and Situations,” Journal of the Korean Institute of Information scientists and Engineers, Vol.15, No.2, 2010, pp.232-236.

[2] O. Jung-Min, M. Nam-Mee, "Preference Element Changeable Recommender System based on Extended Collaborative Filtering,” IEEK journals CI, Vol.47, No.4, 2010, pp.18-24.

[3] Keyword: Culture [online database], http://en.wikipedia.org/wiki/Culture

[4] A. L. Kroeber, and C. Kluckhohn, Culture: A Critical Review of Concepts and Definitions, Random House, 1952.

[5] G. Hofstede, Cultures and Organizations: Software of the Mind, New York, NY: McGraw-Hill., 2005.

[6] B. Wendy, B. Albert, "Culturability: The Merging of Culture and Usability," Proceedings of the 4th Conference on Human Factors and the Web, 1998.

[7] A. Smith et al., “A process model for developing usable cross-cultural websites,” Interacting with Computers 16, 2003, pp.63-91.

[8] M. Aaron, “Cultural Dimensions and Global Web Design: What? So What? Now What?” Aaron Marcus and Associates, Inc. [online database], www.Amanda.com

[9] M. Aaron, “Cross-Cultural User-Interface Design,” Human-Computer Interface Internet Conference, 2001.

[10] Y. Alvin, “Cultural User Interfaces, A Silver Lining in Cultural Diversity,” SIGCHI Vol.28 No.3, 1996.

[11] L. Inseong et al., "An Empirical Study on How the Moderating Effects of Individual Cultural Characteristics towards a Specific Target Affects User Experience: Based on the Survey Results of Four Types of Digital Device Users in the US, Germany, and Russia,” Asia Pacific Journal of Information Systems Vol.19, No.1, 2009. 
[12] H. Edward T and H. Mildred Reed, "Understanding Cultural Differences," INTERCULTURAL PRESS, INC, 1990.

[13] G. Hofstede, "Motivation, leadership, and organization: do American theories apply abroad?," AMACOM, 1980.

[14] G. Hofstede, "Cultures and organizations,” McGraw-Hill New York, 1991.

[15] D. Jack, "Cultural relativism and universal human rights," Human Rights Quarterly, Vol.6, No.4, 1984, pp.400-419.

[16] Keyword: Cultural relativism [online database], http://en.wikipedia.org/wiki/Cultural_relativism

[17] S. H. Schwartz, "Beyond Individualism/Collectivism : New Cultural Dimensions of Values," SAGE PUBLICATIONS LTD, 1994.

[18] S. H. Schwartz, "A theory of cultural values and some implications for work," Applied Psychology : An International Review, Vol.48, issue 1, 1999, pp.23-47.

[19] D. W. Baack, S. Nitish, "Culture and Web Communications," Journal of Business Research 60, 2007, pp.181-188.

[20] AdMob Mobile Metrics, “Metrics Highlights,” http://metrics.admob.com, 2010.5.

[21] eMarketer Editor, “App Usage to Soar in 2010,” eMarketer Article, 2010.1.

[22] O. Jung-Min, M. NamMee, "A Study about Cross-Cultural Content Analysis on Global Website in Korea, US, Japan, China”, Journal of the Korea Society of Computer and Information Vol.15, No.3, 2010. 3.

[23] J. B. KRUSKAL, NONMETRIC MULTIDIMENSIONAL SCALING : A NUMERICAL METHOD, Psychometrika Vol.29, No.2, 1964.

[24] K. Heung-Ryel, Y. Seol-Min, A study for positining of theme park, based on Multi-Dimensional Scaling(MDS), Travel Research Vol.25, No.2, 2010, pp.197-216.

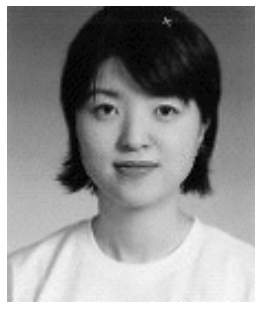

\section{Jung-Min Oh}

She received her B.S. degree in Business Administration from Sookmyung University and her M.S. degree in Digital Media from Seoul University of Venture \& Information, in 1999 and 2008, respectively. She is currently working towards a Ph.D. degree in the Department of IT Application Technology at Hoseo Graduate School of Venture. Her current research interests include cultural user interface, user experience, metadata, and interactive service models.

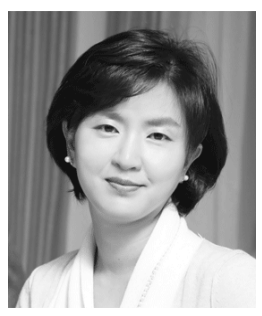

\section{Nammee Moon}

She received her B.S. degree in Computer Science from Ewha Womans University and her M.S. degree in Database from Ewha Womans University, in 1985 and 1987, respectively. She also received a Ph.D. degree in Computer Technology in 1998 from Ewha Womans University. She joined the Department of IT Application Technology at Hoseo University as an associated professor. Her current research interests include interactive digital business models, $\mathrm{HCl}$, service oriented interactive video applications, and metadata. 